\title{
SURDEZ, RECONTO E FORMAÇÃO LEITORA
}

\author{
José Marcos Rosendo de Souza \\ Maria da Conceição Costa \\ Maria Lúcia Pessoa Sampaio
}

RESUMO

As pesquisas com formação leitora têm suscitado algumas discussóes e mudança de posturas ao desenvolvimento de leitores plenos. Contudo, as metodologias que primam pela proficiência de leitores Surdos são escassas. Aqui discutimos a formação leitora de um aluno Surdo a partir de uma pesquisa interventiva, com abordagem cognitiva. A formação leitora de Surdos será possível com adequada metodologia à Surdez.

PALAVRAS-CHAVE: Formação leitora; surdo; estratégias.

\section{Introdução}

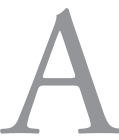

s discussóes sobre formaçáo leitora têm gerado novos posicionamentos acerca do trato dado às metodologias e abordagens utilizadas no contexto escolar, no que diz respeito à leitura. Então, acreditamos que essas discussōes não cessarão, tendo em vista ainda serem comuns práticas, modelos e concepçôes de leitura pautados na decodificação, na extração de informaçóes e na reprodução do código linguístico.

Contudo, ainda devemos nos debruçar sobre tais práticas, discutindo-as, mas transpondo nossas inquietaçóes para outro campo, o da Surdez, pois a formação leitora de sujeitos Surdos também é imprescindível. Neste sentido, com o intuito de abrangermos as discussóes dessa área, objetivamos com este artigo discutir a formação leitora de um aluno Surdo, nos 
utilizando da atividade do reconto com enfoque na abordagem cognitiva.

As inquietaçóes que suscitaram a construção deste artigo surgiram a partir da observação realizada em aulas de Língua Portuguesa no $5^{\circ}$ ano do Ensino Fundamental, em uma escola pública na cidade de Pau dos Ferros/RN, durante quinze dias. Salientamos que essas aulas não dispunham de metodologias, estratégias ou quaisquer outros tipos de recursos que garantissem a formação leitora de um Surdo. Posteriormente às observaçôes, foram realizadas as intervençôes, as quais foram executadas distantes das práticas observadas naquele contexto.

Assim, para que pudéssemos consolidar este trabalho, foram utilizados os pressupostos teóricos de Botelho (2010) e Lodi et al (2013), por abordarem, principalmente, a questão do letramento de minorias Surdas; bem como Skliar (2012), Rojo (2009), Koch e Elias (2012) e Smith (1989), por trazerem princípios e discussóes acerca do ato de ler, seguindo a abordagem cognitiva e interacionista.

\section{Desatando nós, entrelaçando fios: das concepções de leitura à formação leitora}

Como salientamos em nossas primeiras palavras, as discussóes sobre formação leitora, no que tange às dificuldades de formar leitores plenos, têm se consolidado nos últimos anos. É uma temática recorrente talvez porque, como professores, não encontramos soluçóes plausíveis para essa problemática, o que torna a discussão necessária. Entâo, é pertinente, ao iniciarmos este tópico, desatarmos alguns nós no que concerne às concepçóes do objeto da formação leitora - a leitura - e as suas práticas, interligando-as ao Sujeito em questão.

$\mathrm{O}$ trato dado à leitura no contexto escolar tem gerado uma emaranhada e confusa prática de formação de sujeitos leitores, pela qual a trama do sentido das palavras se perde nos ritos de repetição de sons, das cópias enfadonhas e do preenchimento de lacunas. Como bem salienta Angela Kleiman (2012), são atividades áridas e tortuosas, pelas quais fios entrelaçam-se em uma única cor, monocromáticos em sentido.

Os primeiros nós aparecem a partir desse entrelaçar de fios metodológicos, das práticas de leitura utilizadas no contexto escolar. Ao tentarmos desfazê-los compreendemos que as concepçóes do ato de ler são subordinadas ao tipo 
de ensino e concepção que se tem da língua, a saber, língua enquanto expressão do pensamento, código e interação, preconizadas nos postulados travaglianos.

Pela concepção de língua enquanto expressão do pensamento, compreendemos que: “[...] as pessoas não se expressam bem porque não pensam. A expressão se constrói no interior da mente, sendo sua exteriorização apenas uma tradução" (TRAVAGLIA, 2006, p. 21). Por essa concepção, entrelaçam-se perspectivas de ensino pautadas na palavra do outro que é tecida na prescrição, ou seja, o fio que conduz a aprendizagem é dito e repetido, até que seja captado. Aprender, nesse caso, torna-se sinônimo de reproduzir, sobretudo, as intenções do outro.

Não se espera do sujeito aprendiz outra atitude responsiva senão aquela que o leva à passividade, tendo em vista que ele se encontra amarrado aos nós de um modelo pré-estabelecido. Dentro do ensino de língua, o intuito dessa perspectiva é possibilitar a reprodução do modelo linguístico consubstanciado em norma e/ou padrão.

Ao relacionarmos isso à leitura, convém apontar os postulados de Ingedore Koch e Vanda Elias ao tecerem as concepçôes de leitura modulada a essa concepção de língua. As autoras salientam que:

A leitura, assim, é entendida como a atividade de captação das ideias do autor, sem se levar em conta as experiências e os conhecimentos do leitor, a interação autor-texto-leitor com propósitos constituídos sociocognitivo-interacionalmente. O foco de atenção é, pois, o autor e suas intençôes, e o sentido está centrado no autor, bastando tão somente ao leitor captar essas intenções (KOCH; ELIAS, 2012, p. 10).

O emaranhar-se às ideias de outrem obriga o leitor a captar e se amarrar às intençôes previamente construídas pelo autor. Isso logicamente consubstanciado nas atividades amargas de enrolar palavras, sentenças, até que as intençóes do autor e leitor sejam um só bolo de fio. Nessa perspectiva de formação leitora, atar-se ao domínio da palavra de outrem é imprescindível para tecer fios de compreensão e fazer fluir o sentido.

Ao tentarmos desatar os nós dessa concepção, nos convém ressaltar que essa prática é comum no processo de apropriação da palavra, do aprender e 
geralmente relacionamos somente aos alunos ditos "normais". Esquecemos, assim, que em uma mesma sala de aula também estão presentes alunos que apresentam diferentes peculiaridades, a exemplo, a Surdez. Se essa prática de se enrolar as palavras é enfadonha para aqueles - alunos normais -, imaginemos para alunos Surdos, os quais precisam se entrelaçar à palavras de uma língua que não lhes pertence, a saber, a Língua Portuguesa.

Neste sentido, Ana Claudia B. Lodi (2013, p. 40) e outros autores trazem essa discussão ao salientarem que por esse fio "Desvaloriza-se aquilo que o surdo tem a dizer, da forma como o diz. Esclarecemos. A língua de sinais não é considerada como própria para o desenvolvimento e a apropriação dos conhecimentos veiculados social e culturalmente e nem tampouco para se ter acesso à língua portuguesa”.

Mas, compreendemos que isso não decorre simplesmente deste contexto contemporâneo, o hoje. É necessário perceber que a sala de aula se constitui um contexto sócio-histórico, no qual se entrelaçam fios ideológicos. Dizemos isso porque durante o Século XVIII desenvolveu-se a concepção de aprendizagem para Sujeitos Surdos pautada no Oralismo, pela qual eles deveriam dominar a Língua Oral (uma língua da maioria Ouvinte, língua que não lhes pertencia) (SOUZA, 2015).

Em todo caso, mesmo que não esteja presente o Oralismo, amarra-se seu pressuposto ideológico - o domínio da língua falada pela maioria - aos métodos do aprender a ler, o que impede que o Surdo se desenvolva enquanto leitor, tendo em vista que a Surdez, nesta concepção da formação leitora, o impede de captar o sentido impresso nas palavras faladas do outro.

Se o ensino prescritivo traz essas acepçóes sobre a formação leitora, sobre o ensino descritivo outras concepçóes são desenrolados que denotam a funcionalidade da Língua Portuguesa, em certos contextos. Então, a aprendizagem centra-se no domínio das funçóes do código, pelo qual o aprendiz amarra fio a fio, até produzir um som e posteriormente relacioná-lo a um único sentido.

Essa prática, de acordo com as contribuiçóes de Travaglia (2006, p. 22), trata do funcionalismo linguístico, ou como o mesmo salienta: "[...] a língua é vista como um código, ou seja, como um conjunto de signos que se combinam segundo regras, e que é capaz de transmitir uma mensagem, informaçóes de um emissor a um receptor”. 
Por essa prática monológica, o leitor aprende a decifrar incessantemente as palavras até que essas estejam tecidas entre si, amarradas em sua memória, prontas para o uso. De fio em fio, de palavra em palavra, o leitor tece o texto, até que esse lhe faça sentido, pois se o foco são palavras, somente essas construirão o tecido semântico.

Parece-nos que fiar o fio das palavras consiste em trazê-las do dicionário, amarrá-las ao sentido e falá-las. Nada é mais pertinente do que saber usar em determinado contexto a palavra certa, porque certas palavras acabam por se desamarrar de certos significados, e não mais significar. Entretanto, conforme Carlos Skliar (2012, p. 37):

Náo existe dicionário que possa ser aquilo que foi, é e será a palavra. No dicionário, a palavra é um dever ser ontológico (grifos do autor). Nele repousam somente os restos aparentes das palavras, sua estática languidez, sua verdade sempre trêmula e aterrorizada.

Contudo, as práticas de leitura que seguem essa concepção exaurem o leitor e esse, afadigado, acaba por se perder em tantos fios, em tantos novelos de palavras que trazem apenas um significado. Então, se fazem presentes nessa prática de formação leitora as atividades que primam pela decodificação e, posteriormente, a decifração, ou seja, para significar é preciso que o leitor desemaranhe a trama codificada.

Nesta perspectiva, Ingedore Koch e Vanda Elias (2012) caracterizam esse tipo de atividade como reprodução e reconhecimento, já que o foco do leitor estará sempre no texto. Parece-nos que, para os tecelóes dessa prática de formação de leitores, o significar repousa somente na superfície textual, na aparente densidade e forma que as palavras opacas ocupam, nos nós frouxos, esquecendo eles que o sentido está amarrado em nós apertados no interior do tecido do texto.

Acerca da opaca cor (de significados expressos na estrutura aparente) dessas palavras ou do fazer leitor, Frank Smith (1989, p. 42) diz que: "[...] são a parte da linguagem acessível ao cérebro através dos ouvidos (grifo nosso) e dos olhos. [...] A estrutura aparente é a 'informação’ visual da linguagem escrita - a fonte de informação que o leitor perde quando as luzes se apagam - mas também é parte da linguagem falada [...]". 
Relacionando essa prática à formação de leitores Surdos, é possível percebermos a fragilidade dos fios que são usados para isso, pois há a restrição do significar ao léxico da Língua Portuguesa (L2), denotando que quanto mais palavras forem apreendidas pelo leitor Surdo, mais ele poderá compreender o tecido textual. Essa concepção de aprendizagem e/ou de formação leitora encapsula o desenvolvimento tanto Língua de Sinais (L1) quanto da Língua Portuguesa, tendo em vista que o Surdo necessitará apenas do código linguístico de outra Língua.

Novamente é preciso trazer os fios da história para provarmos que essas práticas são decorrentes de outro contexto. No século XIX, preconizou-se a ideia de que a Surdez era uma barreira comunicativa que deveria ser vencida e a partir disso veicularam-se os ideais dos métodos da Comunicação Total (a escrita, leitura orofacial, sinais), os quais permitiam ao Surdo se comunicar (SOUZA, 2015).

Mesmo abrangendo a possibilidade para que se efetivasse a comunicação, é preciso o domínio do código. Paula Botelho (2012, p. 62) afirma que essa perspectiva "[...] de construção de sentido do texto está associada a ideia do domínio de palavras. Os surdos se habituam a parar nas palavras desconhecidas, como se o sentido fosse lexicalizado."

Essas práticas já mencionadas entrelaçam-se aos ritos de escolarização da palavra: o corte, a separação e o encaixar, isto é, o corte - os fios são cortados do tecido da realidade como se o significar independesse da trama contextual; a separação - por ela isolam-se os fios; o encaixar - extrai-se a profundidade e a força, pelas quais se firmam os nós do significar.

Acerca disso, Carlos Skliar (2012, p. 55) expóe que: “[...] ao separar-se o corpo da palavra e ao separar o outro de seu corpo e de sua palavra, só nos resta uma esmaecida vociferação que não anuncia nem enuncia nada. Um grito antecedido de outro grito que antecipa outro grito." Esmaecer as palavras é uma prática que deve ser mantida distante de qualquer contexto que envolva a formação de leitores, principalmente de Surdos. Então, apenas aquelas práticas que avivem as palavras, que as façam torcer e retorcer-se em significados, poderão formar um leitor Surdo.

Aludimos aqui à concepção de Língua enquanto interação, forma e processo, por ser um lugar de ação, contexto, fluxo enunciativo. Travaglia (2006, p. 23) afirma que: "[A língua] é pois um lugar de interação humana, de intera- 
ção comunicativa pela produção de efeitos de sentido entre interlocutores, em uma dada situação de comunicação e em um contexto sócio-histórico e ideológico.” Por essa concepção compreendemos que o ato de ler não se restringe somente à captação de ideias de outrem e tampouco a decifração do código linguístico, mas, sobretudo, cabe ao leitor operar sobre o texto.

Da descrição ao ensino produtivo, percebemos que a leitura nessa última perspectiva de ensino é, sobretudo, dialogicizar, fazer com que os fios do sentido fluam de outros contextos, em uma dialógica ${ }^{1}$ ininterrupta, pela qual a trama semântica é constantemente renovada. Então as práticas de leitura passam a significar, tendo em vista que estarão ligadas aos fios contextuais (contexto do leitor e/ou contexto de uma obra literária).

Por esse fio dialógico, compreendemos que a leitura não é apenas o pensamento de outro e tampouco objeto estático, mas "[...] uma atividade na qual se leva em conta as experiências e os conhecimentos do leitor" $\mathrm{KOCH}$; ELIAS, 2012, p. 11), já que o significado está para além das palavras: faladas ou escritas (SMITH, 1989).

Os fios oriundos dessa prática não restringem o leitor àquelas tarefas amargas já mencionadas, mas possibilita que esse se refaça enquanto sujeito social a partir de suas experiências enquanto Leitor, ou como bem tece Angela Kleiman (2012, p. 29): "[...] ler é a atividade em que ressignificamos a palavra, apoiados na nossa experiência prévia [...]”. A partir disso, ler passa a ser um processo dialético, pelo qual o sujeito se refaz ao refazer a palavra, significa ao significar o mundo.

Neste sentido, acreditamos que somente esse tipo de prática poderá possibilitar a formação de leitores plenos, já que outras práticas mostraram-se insuficientes, sobretudo, no desenvolvimento de leitores Surdos. Nessa perspectiva de prática de leitura que deve ser efetivada pelo Bilinguismo (modalidade de ensino para Surdos, pela qual se faz uso da L1 e L2 - modalidade escrita (SOUZA, 2015)), espera-se que o fazer leitor seja efetivado em Língua de Sinais. É necessário esclarecermos que não é apenas a utilização de outra Língua, mas considerar suas peculiaridades e o valor que ela tem para seu falante.

Acreditamos que impressas a isso também estão as possibilidades de aprendizagem, pois criar condiçóes para a formação de um leitor pleno sem

1 Os termos dialógica, dialogicizar, outrem/outro, atitude responsiva, refrate e domínio autoral nos remetem aos postulados teóricos do filósofo russo Mikhail Bakhtin. 
fazer uso de sua língua materna torna-se impossível; seria o mesmo que formar um leitor brasileiro utilizando-se da língua inglesa. Diante disso, consideramos pertinente lançar outro olhar sobre essa prática e talvez fiarmos outros fios metodológicos, já que a língua utilizada no processo é estritamente visual.

Ao partirmos desse pressuposto da leitura visual, deparamo-nos com outros nós, já que é preciso encarar o processo de formação de leitores Surdos a partir das linhas do (multi)letramento ou da semiose (ROJO, 2009), nas quais a leitura passa a ser atividade social e desenvolvida também pela visão. Nesse sentido, somente os pressupostos dessa área dariam concretude a esse tipo de leitura por relacionarem-se à semiótica, na qual não só a palavra significa, mas também a imagem e o sinal.

A leitura nesse novelo teórico não se restringe a apreensão da linguagem escrita, mas ao domínio das linguagens. Para tanto, torna-se urgente revermos as práticas já desenvolvidas e renová-las, e para isso é preciso fazer uso dos multiletramentos - práticas sociais desenvolvidas pelos indivíduos para se ajustarem à sociedade; e dos letramentos multissemióticos - o contexto contemporâneo exige que a noção de letramento seja ampliada para o campo das outras semioses (imagem, expressão corporal, cores) (ROJO, 2009).

A partir da extensão desta corrente teórica, percebemos fecundidade em suas práticas, pois pretendemos em nossas intervençóes fazer uso da prática de letramento, mas distanciando-nos do trivial fiar fios para ler e escrever, possibilitando ao leitor através da imagem tecer outros fios, com outros significados.

\section{Trama e tecido: reconto para prática da formação leitora}

As observaçóes realizadas com este artigo surgiram da necessidade de constatarmos se havia rupturas nas atividades que primavam pela formação leitora do Sujeito envolvido nessa pesquisa. Então, pudemos perceber exercícios fadigosos para um leitor em formação, pois o que se estabelecia nas aulas das quais o Sujeito era interlocutor era o domínio da Língua Portuguesa a partir da memorização, transcrição e preenchimento de lacunas.

Diante disso, elaboramos atividades interventivas que tiveram como suporte a Língua de Sinais para viabilizar a apreensão da leitura pelo Sujeito em questáo e para isso optamos pela atividade de reconto, pautado na leitura do 
conto Chapeuzinho Vermelho, versão baseada na obra de Charles Perrault (1697).

Optamos por essa narrativa por dois motivos: $1^{\circ}$ ) é um clássico da literatura universal; $2^{\circ}$ ) o Sujeito Surdo, mesmo frequentando o $5^{\circ}$ do Ensino Fundamental, ainda não havia tido acesso àquela obra. Então, em primeiro momento possibilitamos o contato entre leitor e obra, o qual ocorreu através da contação em LIBRAS da narrativa utilizada. Posterior a esse encontro, deu-se início a atividade que possibilitou as nossas discussóes.

As primeiras inferências sobre formação leitora partem do uso do reconto como possibilidade para o desenvolvimento do leitor. Este tipo de atividade requer do leitor o domínio de uma narrativa que lhe servirá de texto base ou modelo para uma nova narrativa.

Assim, na ação de recontar, o sujeito move as estruturas textuais e tece uma nova trama, um novo tecido que poderá trazer em si as marcas do leitor, pois de acordo com Umberto Eco (1994, p. 7) “[...] numa história sempre há um leitor, e esse leitor é um ingrediente fundamental não só do processo de contar uma história, como também da própria história."

Por isso, o (re)contar requer do leitor compreensão tanto do que lê quanto do que (re)conta, isto é, a ação aplicada nesse tipo de atividade não é limitada simplesmente a reprodução de um texto, mas na criação de uma nova história, e para isso é necessária a compreensão (SALLES; PARENTE, 2004).

Subentendemos, com isso, que recontar está para além de reproduzir, é, pois, mover estruturas cognitivas para produçáo de uma outra malha textual. No entanto, é necessário salientar que de acordo com a percepção do leitor, aquela malha poderá ser semelhante ou não ao texto base.

A esse respeito consideramos o seguinte posicionamento:

[...] o texto em sua totalidade é organizado em torno de uma microestrutura (relação semântica construída em torno das frases que constituem o texto) e uma macroestrutura (relacionado à compreensão global do texto). Compreendemos que através do reconto o indivíduo reorganiza a microestrutura de acordo com suas percepçóes pessoais, sem comprometer a macroestrutura. (SOUZA, 2015, p. 93) 
Partindo desse princípio, inicialmente é preciso compreender as peculiaridades do texto base, e a partir disso verificar se houve o reconto realmente, isto é, se ocorreu a (re)estruturação da narrativa. Neste caso, a narrativa utilizada em nossa intervenção se enquadra no gênero Conto Maravilhoso, pois contraria o universo real ao apresentar personagens que realizam açôes inimagináveis (GOTLIB, 2006).

Além desse aspecto, outro que podemos apontar é a organização estrutural da narrativa, já que todo texto está disposto em torno de uma estrutura lógica que encadeará o sentido impresso na trama textual. Para isso, os fatos narrados estão organizados em: orientação, complicação, ação ou avaliação, resolução, conclusão ou moral (VIEIRA, 2001, p. 602), e essa trama ou macroestrutura organizacional, poderá ser cortada, recortada e tecida novamente durante o reconto do Leitor.

Neste sentido, para compreendermos de modo mais preciso essa macroestrutura e de que forma ela é alterada no reconto é necessário a definirmos dentro da narrativa utilizada. Do seguinte modo apresentamos os aspectos macroestruturais:

Orientação - é o macro que corresponde ao contexto situacional, tempo e peculiaridades das personagens (VIEIRA, 2001). Na narrativa que nos serviu de conto base, esse aspecto é identificado nas descriçóes explícitas e implícitas do: contexto situacional, como na descrição do bosque (belo bosque, campo florido e atalhos perigosos); tempo, cuja descrição nos remete à descrição cronológica (toda semana e o dia estava bonito); e na descrição das personagens: a mãe da menina (cuidadosa e atenciosa), o lobo (mau) e Chapeuzinho Vermelho (contente e desobediente);

Complicação - corresponde às açóes que alteram o momento inicial da narrativa. Na narrativa utilizada nas intervençóes, isso é identificado a partir do momento em que Chapeuzinho Vermelho se perde no bosque. Esta ação determina a próxima, pela qual há o encontro entre a Menina e o Lobo Mau.

O macro complicação interliga-se diretamente ao macro da ação ou avaliação, já que esse é alterado em decorrência do macro anterior, isto é, em decorrência da complicação a ação é transformada, provocando as reaçóes da personagem (VIEIRA, 2001). Na narrativa utilizada as alteraçóes são percebidas quando o encontro dos dois personagens (Chapeuzinho Vermelho e Lobo Mau) resulta no distanciamento da menina de seu destino e a ida do Lobo para casa da Vovó. 
Resolução - consubstancia-se em um novo estado, que difere do estado inicial da narrativa, isto é, as açóes realizadas pelos personagens resultam no desenrolar da trama, culminando em um estado de balanço final (VIEIRA, 2001). Na narrativa que nos serviu de base para o reconto, é identificado quando o Lobo Mau chega na casa da Vovó e aguarda pela chegada da Menina. Além disso, o bicho devora tanto a avó quanto a menina, ocasionando novamente em um novo resultado quando se faz presente a figura do Caçador que abre o animal e as retira com vida da barriga.

Conclusão ou Moral - o término da narrativa ou o desfecho final ocorre no momento em que é construída uma moral, que é desencadeada pelas consequências da narrativa (VIEIRA, 2001). A moral construída e o ensinamento produzido pela narrativa ocorrem em seu término, quando a Chapeuzinho Vermelho entende que a desobediência pode trazer consequências.

Sendo assim, coube-nos compreender e perceber de que modo essas peculiaridades estavam impressas no reconto do Sujeito-Leitor desse trabalho. A partir da nossa contação, ele pode realizar o seu reconto em LIBRAS e obtivemos o seguinte produto:

\section{MULHER^PEQUEN@1sir CASA ${ }^{2}$. (1sandar) CAMINHO (1sencontrar2s) LOBO. LOBO 1scomer DUAS.}

Inicialmente devemos desprezar a crença de que a LIBRAS é a Língua Portuguesa Sinalizada, ou a de que ela se sustenta em sua gramática. Diferentemente de tal percepção, precisamos esclarecer que é uma língua própria das comunidades Surdas brasileiras e por isso traz em si as peculiaridades e o modo como este povo percebe sua realidade. Logo, por ser outra língua tem gramática e estrutura diferentes da Língua das comunidades ouvintes, o que explica o modo como foi transcrito o reconto do Sujeito-Leitor.

É perceptível que o reconto realizado pelo Sujeito apresenta certa escassez de detalhes, pois o mesmo traz em si apenas as informaçóes essenciais da

2 O reconto foi transcrito de acordo com a representação da LIBRAS em glosas, isto é, escrita de acordo com a execução dos Sinais. Interpretando para Língua Portuguesa, temos os seguintes enunciados: A menina saiu de casa; Andando pelo caminho encontrou o Lobo; O Lobo comeu as duas. 
narrativa. No entanto, isso não empobrece a sua produção, pois, de acordo com a estrutura organizacional, traz as remiçôes elementares (referimo-nos aqui aos traços particulares como as personagens e suas açôes) que fazem lembrar a narrativa base.

Por essa estrutura é possível perceber a coerência referencial, pois essa se faz presente quando a nova produção tende a repetir elementos do texto base. Então, compreendemos por Coerência Referencial a manutenção ou a presença de elementos do texto base no reconto (SOUZA, 2015). Podemos evidenciar isso ao analisar a seguinte organização:

Orientação - MULHER^PEQUEN@IR CASA, para esse macro do texto, o Sujeito-Leitor se refere à visita da Chapeuzinho Vermelho à Vovó. Essa ação desencadeia os demais fatos da narrativa, tal qual a versão utilizada para essa intervenção;

Complicação e ação ou avaliação - (1sANDAR) CAMINHO (1sENCONTRAR2s) LOBO, o contador restringe este trecho da narrativa ao encontro da Chapeuzinho Vermelho com o Lobo Mau. É perceptível que não há a presença do diálogo entre esses dois personagens, o que no conto base é a ação que desencadeia a reação da personagem, pela qual o Lobo se dirige a casa da Vovó, assemelhando-se ao conto base, o que se configura, também, na resolução, tendo em vista que a ação desse trecho faz com que haja o encaminhamento do último trecho do reconto;

Conclusão ou Moral - LOBO COMER DUAS, no reconto analisado, percebemos que a macroestrutura da narrativa se distancia do conto base, tendo em vista que ambas estão centradas em um único trecho. Desse modo, o diálogo entre o Lobo Mau (disfarçado da Vovozinha) e a Chapeuzinho Vermelho aqui não foi rememorado, logo, essa ação compreendida como essencial para desencadear o fim da narrativa não existe e tampouco desencadeia o fim trágico do vilâo. Diante disso, inferimos que ocorreu uma alteração macroestrutural, transformando esse reconto em uma nova narrativa.

Em relação a isto, salientamos que esses macros se enquadram em um tipo específico de narrativa, que é a de intriga mínima, pois se inicia com uma situação estável, mas se diferencia, unicamente, por não trazer a estabilidade final, de acordo com o que pode ser compreendo a seguir: 
A intriga mínima completa consiste na passagem de um equilíbrio para outro. Uma narrativa ideal começa com uma situação estável que uma força qualquer vem perturbar. Disso resulta um estado de equilíbrio; pela ação de uma força de sentido contrário, o equilíbrio é restabelecido (TODOROV, 2003, p. 160).

É perceptível que, mesmo seguindo a estrutura estabelecida pelo conto base, o reconto apresenta quebras organizacionais quando os comparamos (conto e reconto), mesmo havendo a tentativa e comprometimento do Sujeito em seguir a organização original. Então, inferimos que os fios da narrativa tecidos pelo Sujeito-Leitor ora se amarram ao conto original e ora se torcem em um fio próprio, fazendo com que uma nova narrativa surja.

As brechas presentes no reconto ocorrem em decorrência da experimentabilidade entre o Sujeito-Leitor e o conto base e isso significa que a interação não foi suficiente para consubstanciar no fechamento das ausências (ISER, 1999). A partir disso, inferimos que somente a interação, o diálogo ininterrupto leitor-texto poderá fortalecer a formação leitora de Surdos, e ainda, no caso de atividades de recontos, isso garantirá produções mais precisas, não limitadas apenas às informaçôes principais da narrativa.

Relacionamos isso às particularidades do Sujeito-Leitor (sendo visto aqui como um recontador de história) ao tecer os fios de sua história, isto é, o tecelão do reconto tem características que estão intrínsecas à contação. Já que "A voz do contador, seja oral ou seja escrita [ou seja sinalizada], sempre pode interferir no seu discurso. Há todo um repertório no modo de contar e nos detalhes (grifos da autora) do modo como se conta" (GOTLIB, 2006, p. 13).

Em relação aos fios da narrativa rememorados pelo Sujeito-Leitor, eles são provenientes da trama construída no plano cognitivo, no qual os dados da realidade podem ou não permanecer em sua memória. No caso das narrativas, isso ocorre em decorrência dos processos de estocagem (o primeiro contato com o texto base), retenção (arquivamento das informaçôes relevantes para o Sujeito) e rememoração (relembrar), pelos quais a trama de uma nova narrativa ou a repetição da base é tecida $(\mathrm{KOCH}, 2003)$.

Ao analisarmos o reconto do Sujeito-Leitor, percebemos que alguns fatos do texto base perderam-se no decorrer do processamento no plano cognitivo, mais especificamente na retenção daqueles fatos, já que os mesmos ao serem 
rememorados se apresentam incompletos, se compararmos com a narrativa utilizada. Então, esse reconto, mesmo mantendo a coerência referencial com o texto base, por aquilo que já explicitamos anteriormente, sua completude no plano cognitivo é outra.

Isso ocorre, primeiramente, em decorrência do processamento do texto base, que ao ser transposto ao plano cognitivo, mesmo apresentando linearidade, ele é processado em módulos isolados.

O texto base é coerente, assim, seus elementos estão conexos. É claro que, caso as pesquisas requeridas pela memória de longo prazo solicitadas pelo modelo não são executadas, o texto base será, então, incoerente. Ou seja, o texto será construído por inúmeros grupos separados (SOUZA, 2015, p. 81).

Em segundo momento, nos módulos, que foram processados isoladamente, são armazenadas apenas as informaçóes que tiveram maior significância para o Sujeito-Leitor. O que explica estarem presentes no reconto os fatos pertinentes à compreensão global da narrativa, isto é, cada módulo guardou apenas as informações principais e mesmo sem as outras ações é possível compreender o enredo construído.

Neste sentido, consideramos o reconto enquanto modalidade preponderante à formação leitora do Sujeito-Leitor desta pesquisa, já que esse tipo de atividade permitiu ao indivíduo retomar o conto base e reconstruí-lo. Não apenas por isso, mas também porque essa atividade possibilitou ao Sujeito-Leitor exercitar seus conhecimentos sociocognitivos-interacionistas (pois o reconto foi realizado em LIBRAS), corroborando que para o desenvolvimento do Leitor é preciso considerar suas experiências anteriores ao ato de decodificar $(\mathrm{KOCH}$; ELIAS, 2012); até mesmo suas experiências sensoriais com sua Língua Materna.

Essa experiência sensorial de saborear o conto e o reconto através dos olhos e mãos se enquadra dentro das possibilidades dos multiletramentos e letramento multissemiótico (ROJO, 2009), tendo em vista que a LIBRAS é uma língua de modalidade visuo-espacial e por isso as impressôes construídas por seu falante se distanciam do código linguístico impresso na escrita.

Ainda podemos ressaltar que a representação da LIBRAS em Língua Portuguesa nos permite perceber a relação entre instituição social e Sujeito-Leitor, 
pois o reconto traz a percepção particular do Sujeito-leitor, comprovando que para significar a palavra é preciso que ambos se entrelacem (SKLIAR, 2012), remetendo-nos à Língua enquanto atividade produtiva, interativa, dialógica (TRAVAGLIA, 2006).

A partir disso, compreendemos que o reconto enquanto atividade dialógica possibilita que o leitor refrate o conto base, isto é, esse tipo de produção permite que sejam feitas alteraçoos (inferências, acréscimos e supressão) no texto base. Isso contribui para a Formação Leitora do indivíduo, pois é preciso que ele tenha domínio autoral (tendo em vista que se trata de uma nova produção) e conhecimentos tanto de mundo quanto do texto, os quais contribuem para reorganização estrutural da narrativa.

\section{Considerações finais}

Quando nos propomos a discutir sobre formação leitora corremos o risco de repetirmos alguns dos discursos já construídos teoricamente. No entanto, esses discursos não trazem algo concreto quando queremos formar leitores surdos, ocorrendo assim uma dissociação entre teoria e prática formadora. Por isso, pretendemos nesse artigo discutir a formação leitora de um aluno Surdo, utilizando-nos da atividade reconto.

Ao tecermos os fios teóricos nos deparamos com três possibilidades de ensino de língua - prescritivo, descritivo e produtivo - e consequentemente de modelos de Formação Leitora provindas do saber o que é a Língua. Então, compreendemos que as práticas de Formação Leitora baseadas naquelas concepções se restringem à decodificação, à apropriação das ideias do autor e à prática de interação ou dialógica, respectivamente.

Estas práticas quando relacionadas ao ensino de língua para alunos Surdos fazem emergir fios ideológicos do que é ser Surdo, isto é, aparecem nas atividades as construçóes sociais acerca do Sujeito Surdo, as quais nos remetem ao Oralismo, Comunicação Total e Bilinguismo. Essas práticas de ensino, pelo que percebemos, determinam o que o Surdo deve aprender e pelo que vimos: no Oralismo o indivíduo aprende a língua falada, denotando a expressão do pensamento; pela Comunicação Total há aprendizagem do código; e o Bilinguismo prima pela abordagem dinâmica das Línguas (LIBRAS e Língua Portuguesa). 
Procuramos nos distanciar dos modelos da descrição e prescrição e, consequentemente, do Oralismo e Comunicação Total. Para isso, optamos pela atividade de reconto por possibilitar ao Sujeito-Leitor maior interação e dialogicidade com a obra selecionada. Então, discutimos e analisamos a partir da abordagem cognitiva, pela qual compreendemos que a produção do reconto passa pelo plano cognitivo e entrelaça-se às percepçóes pessoais e contextuais tanto do leitor quanto do texto, tornando-se um contributo para Formaçáo Leitora do Sujeito-Leitor.

\section{Referências}

BOTELHO, Paula. Linguagem e Letramento na educação dos surdos: ideologias e práticas pedagógicas. Belo Horizonte: Autêntica Editora, 2009. p. 158.

GOTLIB, N. B. Teoria do conto. 11 ed. São Paulo: Ática, 2006. p. 95.

ECO, U. Seis passeios pelos bosques da ficção. São Paulo: Companhia das Letras, 1994. p. 158.

ISER, W. $O$ ato da leitura: uma teoria do efeito estético. 2 v. São Paulo: Editora 34, 1999. p. 198.

LODI, Ana Claudia B.; HARRISON, Kathryn Marie P.; CAMPOS, Sandra Regina L. Letramento e surdez: um olhar sobre as particularidades dentro do contexto educacional. In: LODI, Ana Claudia B.; HARRISON, Kathryn Marie P.; CAMPOS, Sandra Regina L.; TESKE, Ottmar. (orgs.). Letramento e minorias. Porto Alegre: Mediação, 2013. p. 160.

KLEIMAN, Angela. Oficina de leitura: teoria e prática. São Paulo: Pontes Editores, 2012. p. 155.

KOCH, I. G. V. Desvendando os segredos do texto. 2. ed. São Paulo: Cortez, 2003.

$\mathrm{KOCH}$, Ingedore Villaça; ELIAS, Vanda Maria. Ler e compreender: os sentidos do texto. São Paulo: Contexto, 2012. p. 216.

ROJO, Roxane. Letramentos múltiplos, escola e inclusão social. São Paulo: Parábola Editorial, 2009. p. 127.

SMITH, Frank. Compreender a leitura: uma análise psicolinguística da leitura e do aprender a ler. Porto Alegre: Artes Médicas, 1989. p. 423.

SKLIAR, Carlos. Experiências com a palavras: notas sobre a linguagem e diferença. Rio de Janeiro: Wak Editora, 2012. p. 184. 
SOUZA, José Marcos Rosendo. Entre palavras e sinais: letramento literário, surdez e inclusão. São Carlos: Pedro \& João Editores, 2015. p. 224.

TODOROV, Tzvetan. Poétique de la prose. Tradução de Claudia Berliner. São Paulo: Martins Fontes, 2003. p. 341.

TRAVAGLIA, Luís Carlos. Gramática e interação, uma proposta para o ensino de gramática. São Paulo: Cortez, 2006. p. 248.

VIEIRA, André Guirland. Do conceito de estrutura narrativa à crítica. Psicologia: reflexão e crítica, 2001, 14, p. 599-608.

\title{
DEAFNESS, RETELLING AND READER FOMATION
}

\begin{abstract}
Research on formation of readers has raised some discussions and change of atitudes, to the development of full readers. But, the methodologies that strive for proficiency of Deaf readers there are scarse. We intend to discuss in this article the formation of a reader Deaf through from an interventional research, with cognitive approach. The reader formation of Deaf will be possible with appropriate method to their peculiarities.
\end{abstract}

KEYWORDS: Reader formation; deaf; strategies.

Recebido em: 27/10/2015

Aprovado em: 09/03/2016 